\title{
International Survey on D-Dimer Test Reporting: A Call for Standardization
}

\author{
Giuseppe Lippi, MD ${ }^{1}$ Armando Tripodi, $\mathrm{PhD}^{2,3}$ Ana-Maria Simundic, $\mathrm{PhD}^{4}$ \\ Emmanuel J. Favaloro, PhD, FFSc (RCPA) ${ }^{5}$
}

${ }^{1}$ Department of Clinical Chemistry and Hematology, Academic Hospital of Parma, Parma, Italy

2 Department of Clinical Sciences and Community Health, University

Address for correspondence Giuseppe Lippi, MD, U.O. Diagnostica Ematochimica, Azienda Ospedaliero-Universitaria di Parma, Via of Milano, Italy

3 IRCCS Cà Granda Maggiore Hospital Foundation, Milano, Italy

${ }^{4}$ University Department of Chemistry, University Hospital Center Sestre Milosrdnice, Zagreb, Croatia

${ }^{5}$ Department of Haematology, Institute of Clinical Pathology and Medical Research (ICPMR), Pathology West, NSW Health Pathology, Westmead, New South Wales, Australia,

Gramsci, 14, 43126 Parma, Italy (e-mail: glippi@ao.pr.it; ulippi@tin.it).

Semin Thromb Hemost 2015;41:287-293.

\begin{abstract}
D-dimer is the biochemical gold standard for diagnosing a variety of thrombotic disorders, but result reporting is heterogeneous in clinical laboratories. A specific five-item questionnaire was developed to gain a clear picture of the current standardization of D-dimer test results. The questionnaire was opened online (December 24, 2014-February 10, 2015) on the platform "Google Drive (Google Inc., Mountain View; (A)," and widely disseminated worldwide by newsletters and alerts. A total of 409 responses were obtained during the period of data capture, the largest of which were from Italy (136; 33\%), Australia (55; 22\%), Croatia (29; 7\%), Serbia (26; 6\%), and the United States $(21 ; 5 \%)$. Most respondents belonged to laboratories in general hospitals (208; $51 \%)$, followed by laboratories in university hospitals (104; $26 \%$ ), and the private sector $(94 ; 23 \%)$. The majority of respondents (i.e., $246 ; 60 \%$ ) indicated the use of fibrinogen equivalent unit for expressing D-dimer results, with significant heterogeneities across countries and health care settings. The highest prevalence of laboratories indicated they were using " $\mathrm{ng} / \mathrm{mL}$ " (139; 34\%), followed by “mg/L" (136; 33\%), and " $\mathrm{mg} /$ L" (73; 18\%), with significant heterogeneity across countries but not among different health care settings. Expectedly, the vast majority of laboratories (379; 93\%) declared to

Keywords

- D-dimer

- venous thromboembolism

- thrombosis

- standardization be using a fixed cutoff rather than an age-adjusted threshold, with no significant heterogeneity across countries and health care settings. The results of this survey attest that at least 28 different combinations of measurement units are currently used to report D-dimer results worldwide, and this evidence underscores the urgent need for more effective international joined efforts aimed to promote a worldwide standardization of D-dimer results reporting.
\end{abstract}

\section{Biochemistry and Biology of D-Dimer}

D-dimer is a generic term that refers to a large number of peptides deriving from the breakdown of a stabilized fibrin clot. At variance with the generation of fibrin(ogen) degradation products (FDPs), which increase in the circulation as a result of plasmin-mediated degradation of both fibrinogen and fibrin, D-dimer is produced only when both the blood published online April 3, 2015
Issue Theme Quality in Hemostasis and Thrombosis - Part IV; Guest Editors: Giuseppe Lippi, MD, Emmanuel J. Favaloro, PhD, FFSc (RCPA), and Mario Plebani, MD.
Copyright $\odot 2015$ by Thieme Medical Publishers, Inc., 333 Seventh Avenue, New York, NY 10001, USA. Tel: +1(212) 584-4662.
DOI http://dx.doi.org/ 10.1055/s-0035-1549092. ISSN 0094-6176. 
coagulation and fibrinolytic pathways are concomitantly activated (-Fig. 1). ${ }^{1}$ In brief, after initiation of blood coagulation, fibrinogen is converted to fibrin by thrombin, which enzymatically remove fibrinopeptides A and B from fibrinogen. The resulting molecule initially aggregates to form a labile network of fibrin monomers, which is then stabilized by activated coagulation factor XIIIa (FXIIIa). In this process, FXIIIa catalyzes the covalent linkage of the C-terminal appendages of gamma-chains of adjacent fibrin monomer units, producing a stable cross-link that is effective in ensuring a much greater degree of clot stability in injured vessels, thus preventing excessive bleeding ( - Fig. 1). The further activation of the fibrinolytic pathway leads to a plasmin-mediated degradation of the stabilized fibrin network, with generation of cross-linked (i.e., D-D) FDPs. ${ }^{1}$ It is hence clear that while the enhanced presence in the circulation of FDPs reflects a nonspecific process of both fibrinogen (i.e., primary fibrinolysis) and cross-linked fibrin degradation, an increased concentration of $\mathrm{D}$-dimer containing peptides mirrors a contextual activation of both blood coagulation and fibrinolysis (-Fig. 1). This explains why the measurement of D-dimer is much more specific than FDPs for diagnosing a thrombotic process. ${ }^{2}$

The metabolism of D-dimer after generation in blood is prevalently renal, with minor reticuloendothelial system clearance, displaying a half-life of approximately 6 to 8 hours in patients with preserved kidney function. ${ }^{3}$ The relative increase of D-dimer in plasma also depends on a large number of variables, including the size and location of the thrombus (i.e., patients with distal thrombosis typically have lower D-dimer values than those with proximal thrombosis), the time of measurement after thrombosis, and the estab- lishment of anticoagulant therapy (anticoagulant treatment may considerably limit clot expansion and thus reduce D-dimer generation). ${ }^{4}$ As the results of a physiological aging of the coagulation system, ${ }^{5} \mathrm{D}$-dimer values progressively increase with age, being nearly 5 - to 10 -fold higher in those $>65$ years compared with childhood age. ${ }^{6}$ Increased values are also typically observed in uncomplicated pregnancies. ${ }^{7}$

\section{Clinical Usefulness of D-Dimer}

Despite D-dimer remaining the biochemical gold standard for diagnosing venous thromboembolism (VTE) and disseminated intravascular coagulation (DIC), ${ }^{8-10}$ several biological, clinical, and analytical challenges emerge. First, although an enhanced concentration of D-dimer is a reliable index of thrombosis, rather understandably it can not be specific enough for one thrombotic pathology. ${ }^{11}$ Accordingly, increased D-dimer values are typically found in patients with VTE, ${ }^{12}$ DIC, ${ }^{13}$ but also in those with other thrombotic disorders such as cerebral or retinal vein thrombosis, ${ }^{14,15}$ acute coronary syndrome, ${ }^{16}$ stroke, $^{17}$ peripheral occlusive disease, ${ }^{18}$ acute aortic dissection, ${ }^{19}$ as well as in a large series of conditions that may be associated with hyperactivation of blood coagulation and fibrinolysis. These typically include trauma, ${ }^{20}$ surgery, ${ }^{21}$ severe infection or sepsis, ${ }^{22}$ cancer, ${ }^{23}$ and atrial fibrillation. ${ }^{24}$

Due to the high diagnostic sensitivity (up to 100\%) and relatively low specificity of D-dimer for thrombotic disorders such as VTE or DIC (i.e., 30-70\%), ${ }^{3}$ its measurement does not achieve a satisfactory performance for the effective diagnosis of thrombosis, and must hence be used in combination with prediction rules (i.e., Geneva or Well score) and diagnostic

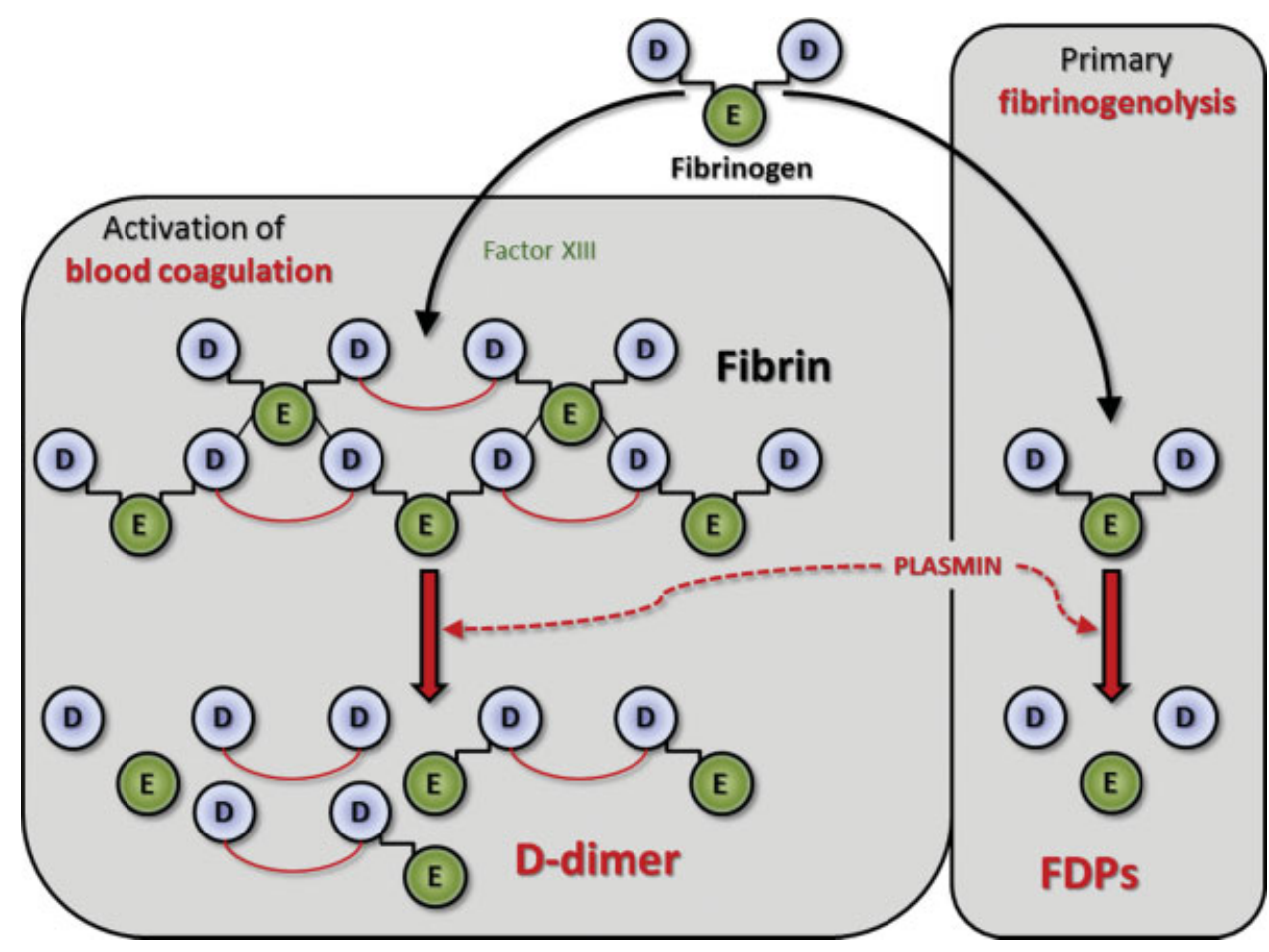

Fig. 1 In vivo generation of FDPs and D-dimer. FDP, fibrin/fibrinogen degradation products. 
imaging (i.e., Doppler ultrasonography, scintigraphy, computed tomography) to increase its positive predictive value. $^{8}$

Another important aspect is related to the still unmet standardization of the analytical techniques used for D-dimer measurement, which mostly entail enzymatic or latexenhanced turbidimetric immunoassays. As previously explained, D-dimer is not a single molecule, but a heterogeneous mix of FDPs containing cross-linked D-D domains (-Fig. 1). This explains why a universal standard has not been successfully produced so far, ${ }^{5}$ and especially why commercial methods, using different monoclonal antibodies against the D-D domain, display imperfect correlations. ${ }^{25,26}$ Although specific recommendations have recently been published, ${ }^{10}$ reporting of D-dimer results is also unfortunately still highly heterogeneous among laboratories across the world. Specifically, results may be reported in terms of Ddimer unit (DDU) or fibrinogen equivalent unit (FEU), and as many as seven different units of measurement are in use (i.e., $\mathrm{ng} / \mathrm{mL}, \mathrm{mg} / \mathrm{L}, \mu \mathrm{g} / \mathrm{L}, \mu \mathrm{g} / \mathrm{mL}, \mathrm{g} / \mathrm{L}, \mathrm{g} / \mathrm{mL}$, and $\mathrm{mg} / \mathrm{dL}$ ). Moreover, results can be also reported, according to a fixed or an ageadjusted cutoff (i.e., [age-adjusted cutoff, $\mu \mathrm{g} / \mathrm{L} \mathrm{FEU}]=$ [age, years]) $\times 10$ ), to increase the test specificity with increasing age. ${ }^{10}$ This problem is not without meaningful implications. Although an external quality assessment program based on commercially prepared lyophilized human plasma spiked with human-derived D-dimer components showed that the rate of results falling within the appropriate range (normal/ negative or abnormal/positive) was remarkably high (i.e., 96$99 \%),{ }^{27}$ it is considered unacceptable that the same patient may receive different results from neighboring laboratories using different means of reporting D-dimer values; this would challenge the direct comparison of longitudinal data, and may also confound busy physicians who are required to distinguish between dozens of different ways that may be used for expressing results.

\section{The Survey}

To the best of our knowledge, only one previous (U.S.-based) survey (with 1,506 responders) has been published (by the College of American Pathologists [CAP]) on the issue of D-dimer results. ${ }^{28}$ Therefore, a specific, five-item questionnaire was developed, to gain a much broader picture of the current standardization of D-dimer results across laboratories worldwide. The leading aspects that were pursued included the originating country of the laboratory, its setting within the health care system (i.e., university hospital, general hospital, private facility, other), the expression of results in DDU or FEU, the unit of measurement (e.g., ng/mL, g/mL, mg/L, g/L, $\mu \mathrm{g} / \mathrm{L}$, $\mu \mathrm{g} / \mathrm{mL}$, and others), and the use of fixed or age-adjusted cutoffs. The online version of the questionnaire is still available at: https://docs.google.com/forms/d/1IVMqgIsZRN_rqbv2PdhPoerRB6UERXdEuCi0Czr-7m0/viewform (Accessed February 10, 2015), and will be kept open to permit ongoing assessment of trends.

The questionnaire was designed and distributed with the platform “Google Drive” (Google Inc. Mountain View, CA). The survey was opened on November 24, 2014 and was disseminated by a variety of means, including newsletters and alerts by national and international scientific societies of laboratory medicine or hemostasis, and was also advertized in two scientific Web sites, "Researchgate" (Available at: https:// www.researchgate.net/. Accessed: February 10, 2015) and "The Fritsma Factor" (Available at: http://www.fritsmafactor.com/. Accessed: February 10, 2015). Data collection for this report was finalized on February 10, 2015, but as mentioned above the survey remains open.

\section{Results of the Survey}

\section{General Response}

A final number of 409 responses were obtained up to the time of data analysis. The geographical distribution and the settings of the responding laboratories are shown in - Fig. 2. Briefly, the largest number of responses were obtained from Italy (136; 33\%) and Australia (55; 22\%), followed by Croatia (29; 7\%), Serbia (26; 6\%), and the United States (21; 5\%).

As regards the setting of the laboratory within the health care system, the majority of respondents belonged to laboratories in general hospitals (208; $51 \%$ ), followed by laboratories in university hospitals $(104 ; 26 \%)$, and then the private sector $(94 ; 23 \%)$. A marginal percentage of respondents (3; $1 \%$ ) declared to be employed within other types of laboratories.

\section{Expression as D-Dimer Unit or Fibrinogen Equivalent Unit}

The responses to the first specific question of the survey, that is expression of D-dimer results as DDU or FEU, are shown in -Fig. 3. The majority of respondents (i.e., 246; 60\%) indicated FEU as the current unit used for expressing D-dimer results. This data compares favorably with the CAP survey, in which nearly $59 \%$ of the responders used FEU. ${ }^{28}$ The frequency of DDU was found to be slightly different across

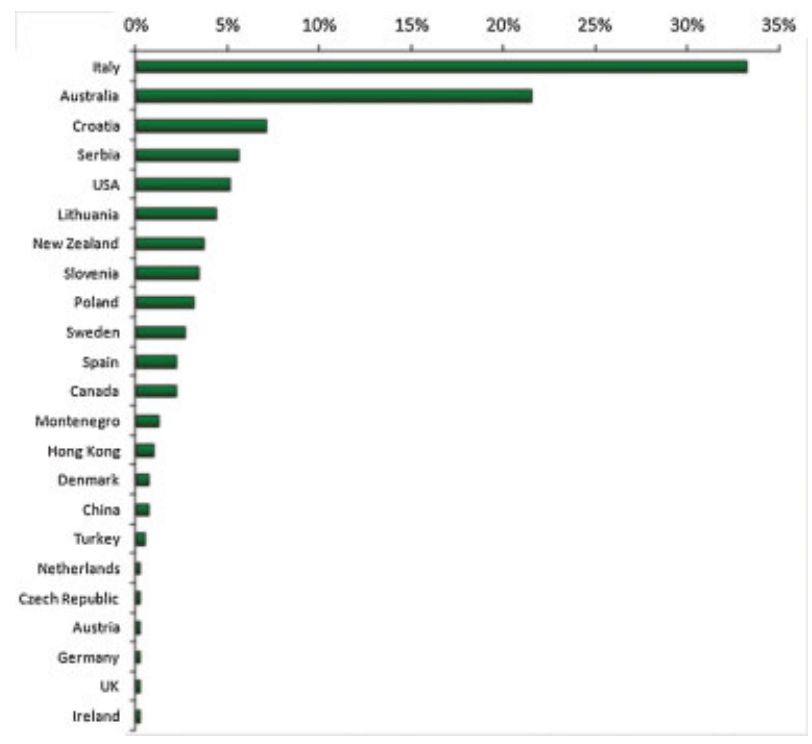

Fig. 2 Country distribution of respondents to the survey. 

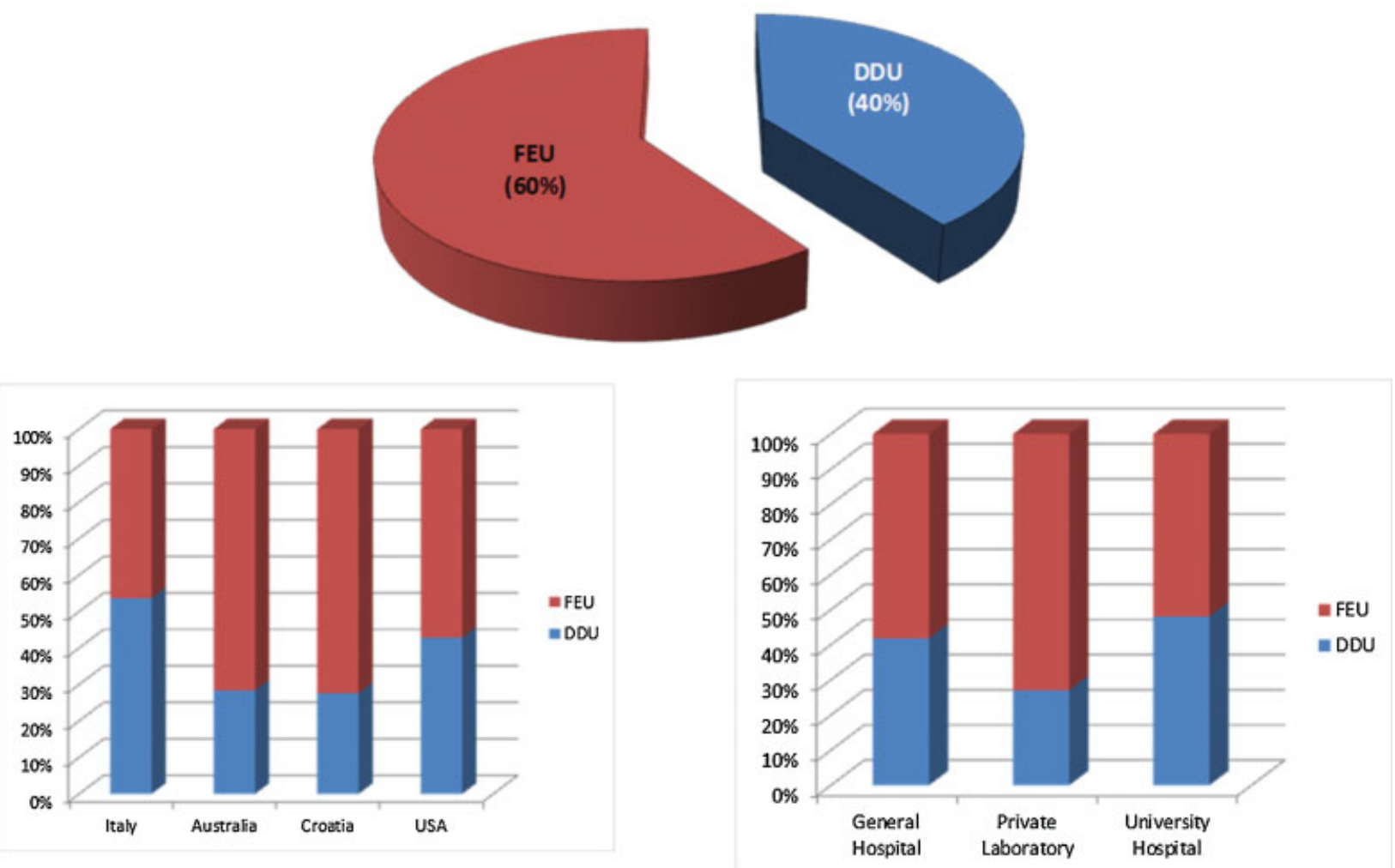

Fig. 3 Use of DDU or FEU for D-dimer reporting among respondents to the survey. DDU, D-dimer unit; FEU, fibrinogen-equivalent unit.

four of the five countries with the largest number of responses in Italy and United States than in Australia and Croatia (chisquare statistic, $16.8 ; p=0.001$ for trend). The prevalence of DDU usage was also found to be higher in the university and general hospital, than in private facilities (chi-square statistic, 9.8; $p=0.007$ for trend) (-Fig. 3).

\section{Units of Measurement}

The responses to the second specific question of the survey, that is the DDU of measurement, are shown in -Fig. 4. Compared with the CAP survey, in which $50 \%$ of the respondents used "ng/mL," followed by "g/mL" (28\%), "mg/L" (20\%), and "g/L" $(2 \%),{ }^{28}$ a significant number of replies indicating " $\mu \mathrm{g} / \mathrm{L}$ " was observed in our study $(73 ; 18 \%$ compared with $0 \%$ in CAP survey). Only two (0.5\%) laboratories in our study were still using qualitative results (i.e., positive/negative). However, as was the case in the CAP survey, ${ }^{28}$ the highest prevalence of laboratories indicated to be using "ng/mL" (139; 34\%), closely followed by $\mathrm{mg} / \mathrm{L}$ (136; 33\%). Unlike the CAP survey, we did not collect any response for " $\mathrm{g} / \mathrm{mL}$." As regards four of the five countries with the largest number of responses, a much greater number of laboratories using "ng/mL" were found in Italy; however, "mg/L" was largely prevailing in Australia and Croatia, whereas " $\mu \mathrm{g} / \mathrm{L}$ " was largely used in the United States (chi-square statistic, 109.1; $p<0.001$ for trend). No significant differences could be observed across the different types of facilities (chi-square statistic, $2.8 ; p=0.827$ for trend) (-Fig. 4).

\section{Age-Adjusted D-Dimer Cutoffs}

The responses to the third specific question of the survey, that is, the use or not of age-adjusted D-dimer cutoffs is shown in - Fig. 5. Expectedly, the vast majority of laboratories (379; 93\%) declared to be using a fixed cutoff for D-dimer test reporting. A direct comparison with the CAP survey is unfeasible, as this item was not present in the U.S.-based questionnaire. ${ }^{28}$ As regards four of the five countries with the largest number of responses, the frequency of centers using ageadjusted cutoffs were higher in Italy, intermediate in the United States, low in Australia and zero in Croatia, but the difference across such countries did not reach statistical significance (chi-square statistic, $7.3 ; p=0.062$ for trend). Similarly, no significant differences could be observed across the different types of facilities (chi-square statistic, 2.3; $p=0.314$ for trend) (-Fig. 5 ).

\section{Discussion}

Although it is now clearly established that most problems in the hemostasis laboratory emerge from the preanalytical phase, ${ }^{29}$ postanalytical events related to reporting and interpretation of test results are still the cause of a large number of diagnostic errors, which can ultimately jeopardize patient safety. $^{30}$

As regards to D-dimer testing, the use of so many different units of measurement is particularly alarming. The physicians, who are not aware of the current lack of standardization of test reporting, may be confused by receiving nonstandardized reports from neighboring laboratories. A paradigmatic example is the use of DDU or FEU ( $1 \mathrm{FEU}=$ $2 \times$ DDU) in two facilities within the same network of laboratories. When a patient is transferred from one facility reporting data in DDU to another using FEU (both using an 

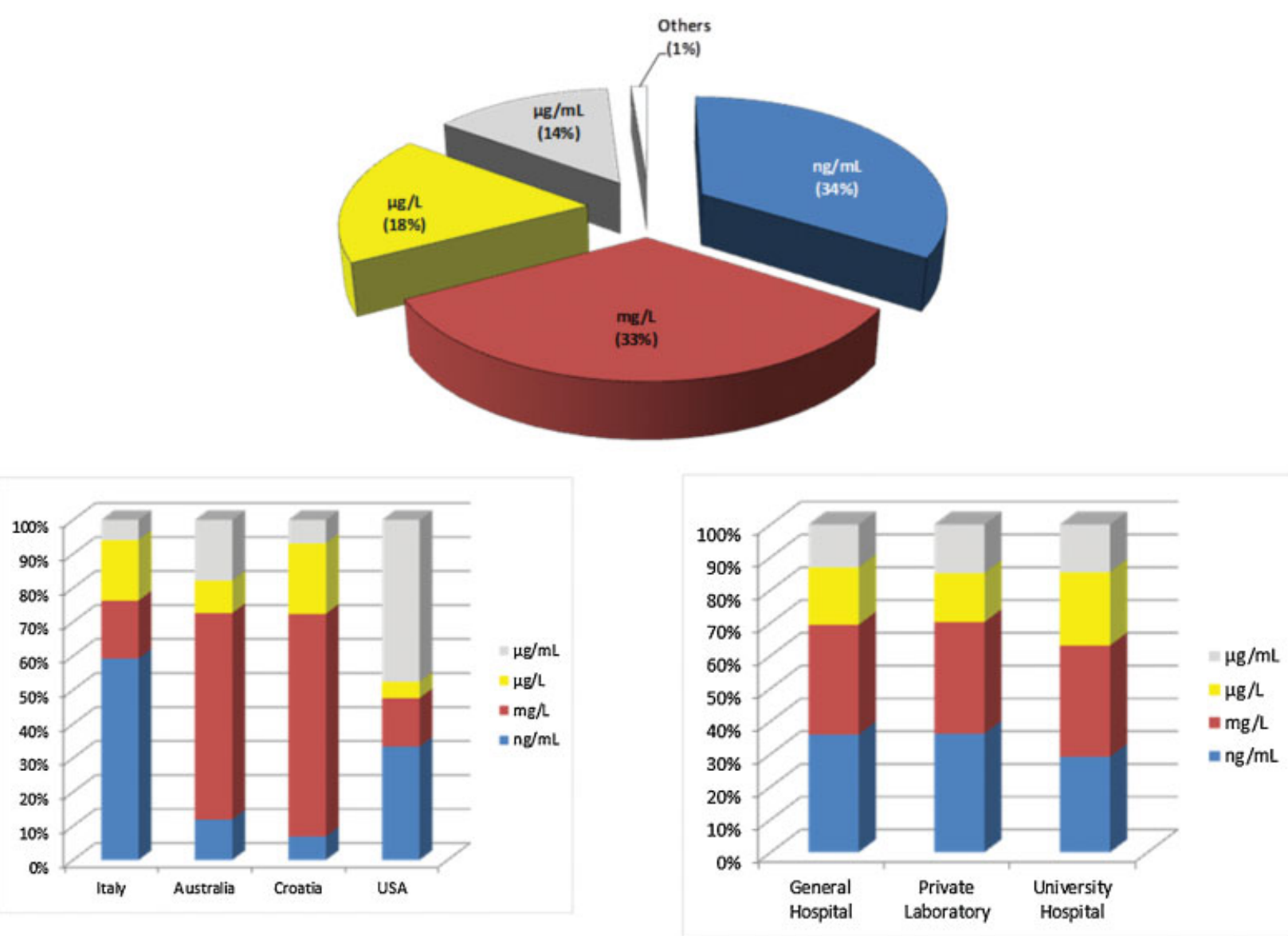

Fig. 4 Use of different measure units for D-dimer reporting among respondents to the survey.

identical unit of measurement, e.g., $\mathrm{ng} / \mathrm{mL}$ ), the expected result in the latter laboratory would be twice as high as that in the former (i.e., $400 \mathrm{ng} / \mathrm{mL}$ DDU $=800 \mathrm{ng} / \mathrm{mL} \mathrm{FEU}$ ). Nonetheless, the busy physicians, especially those working in emergency departments or intensive care units, may overlook the fact that the previous patient data might have been reported in concentration of D-dimer, and they may hence interpret the actual results expressed in FEU as a "pathological" doubling of level. The use of different units of measurement is perhaps less critical, wherein " $\mu \mathrm{g} / \mathrm{L}$ " equals "ng/mL," whereas the values in " $\mu \mathrm{g} / \mathrm{L}$ " are 1,000-fold higher than those in "mg/L" or in " $\mu \mathrm{g} / \mathrm{mL}$," so that they are less likely to be confounded. Another important aspect involves the agerelated changes in blood coagulation, which favor the development of a hypercoagulable state in the elderly, ${ }^{5,31}$ which is ultimately reflected by an age-dependent increase of D-dimer values. ${ }^{6}$ This evidence paved the way to a large number of clinical studies aimed at defining age-dependent D-dimer cutoffs, to further increase the diagnostic specificity of this biomarker in the elderly. ${ }^{6}$ Although specific recommendations to use age-adjusted cutoffs were also published, ${ }^{10,32}$ no precise information before this survey was available as to whether these suggestions have been followed.

Major efforts are currently being placed in harmonizing D-dimer measurements with different methods. ${ }^{33,34}$ Interestingly, the Fibrinogen and Factor XIII Subcommittee of the Scientific Standardization Committee of the International
Society on Thrombosis and Hemostasis (ISTH) has published recommendations about the nomenclature of fibrinogen and fibrin, ${ }^{35}$ but $\mathrm{D}$-dimer was not included.

The first conclusion that can be drawn from the results of this large international survey is that D-dimer is probably the most paradigmatic example of poor standardization of laboratory test reporting in the broad field of laboratory diagnostics. It is noteworthy that 28 different combinations of units of measurement were reported overall by survey respondents ( 2 between DDU or FUE $\times 7$ measurement units $\times 2$ between fixed or age-adjusted cutoff). This scenario is even worse than that previously estimated from the CAP survey. It is also noteworthy that the term D-dimer does not even identify a homogenous analyte, but comprises a mixture of degradation products of stabilized fibrin with molecular weights potentially ranging from 190 to $>10,000 \mathrm{kDa}$ (-Fig. 1). ${ }^{34}$ This obviously makes the expression in a hypothetical "mol/L" standard unit virtually unfeasible. The unit of measurement which is probably more in line with the International System (IS) is " $\mu \mathrm{g} / \mathrm{L}$," which is also essentially the same as "ng/mL." Interestingly, these account for the vast majority of responses collected in our survey $(18 \% \mu \mathrm{g} / \mathrm{L}$ and $34 \% \mathrm{ng} / \mathrm{mL}$, totaling $52 \%$ of overall responses). As regards DDU and FEU, the combination of the latter format with " $\mu \mathrm{g} / \mathrm{L}$ " would generate a cutoff of approximately $500 \mu \mathrm{g} / \mathrm{L}$ FEU for patients aged 50 years and younger, which is the most accurate diagnostic threshold identified in a large systematic 

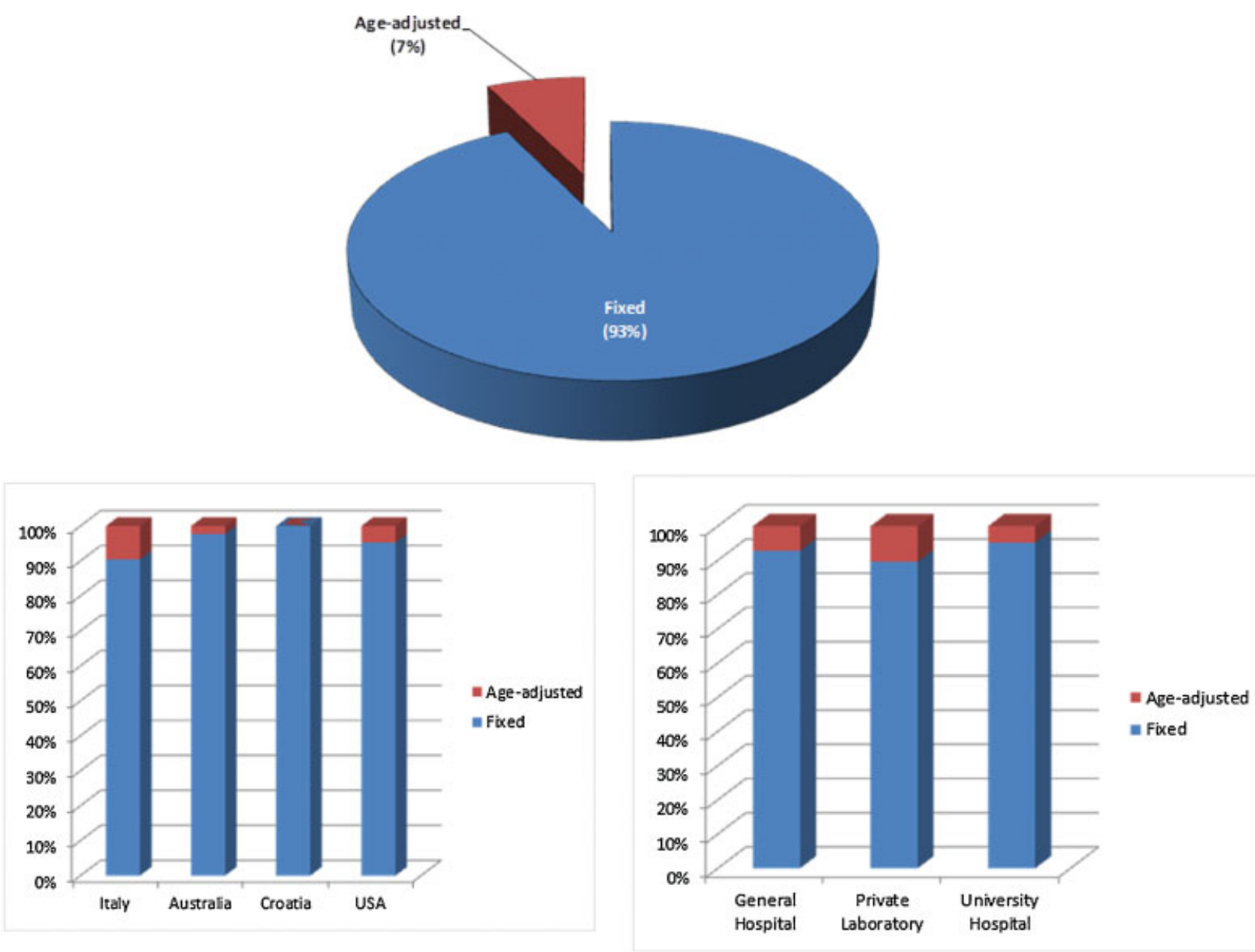

Fig. 5 Use of fixed or age-adjusted cutoff for D-dimer reporting among respondents to the survey.

review and meta-analysis including 13 cohort studies and 12,497 patients. $^{32}$ As regards age-adjusted cutoffs, several lines of evidence now attest that the use of this approach considerably enhances the positive predictive value of this biomarker, with negligible impact on the negative predictive value. ${ }^{32}$ It seems therefore reasonable to suggest that the use of age-adjusted cutoffs should be further promoted for improving the clinical usefulness of D-dimer testing in elderly patients with nonhigh clinical probability.

Understandably, the authors of the current report are not in a position to provide any official recommendations toward the use of one unit or another. Indeed, differences in reporting approach were also identified among the authors of this report. However, the results of the international survey clearly attest that large supranational societies in charge of harmonizing practices within hemostasis laboratories, such as the ISTH or the International Federation of Clinical Chemistry and Laboratory Medicine, should take a lead role to pursue the challenging enterprise of standardizing D-dimer results reporting, along with harmonizing data among different manufacturer products.

It is, however, recognized that the introduction of a widespread standardization of D-dimer reporting also carries many challenges and some mindful drawbacks. First, the adoption of common means of test reporting would go against individual manufacturers' recommendations unless manufacturers agreed on a common approach. This has many additional significant implications, since following manufacturer's recommendations are inherently requirements of continued laboratory practice including accreditation and regulatory conditions. ${ }^{36}$ Second, it will also introduce a further source of variability when attempting to translate cutoffs previously established in large and reliable clinical studies and then adapted to daily practice. Moreover, any change in test practice may lead to confusion of laboratory staff and clinicians using the test, at least in the initial phase of transition toward a new standardized means of expressing results. Therefore, an appropriate policy of information and education should be locally established, to prevent such changes in the units of measurement becoming an additional and unwanted source of confusion for clinicians.

\section{Acknowledgments}

The authors are thankful to the following individuals and groups for support in disseminating or publicizing the survey: Roslyn Bonar and John Sioufi (Royal College of Pathologists of Australasia Quality Assurance Program; RCPAQAP in Haematology), Megan Sarson (Australasian Society for Thrombosis and Haemostasis), Timothy Woods and Ian Jennings (United Kingdom National External Quality Assessment Service for Blood Coagulation; UK NEQAS 
BC), Piet Meijer (External quality Control for Assays and Tests with a focus on thrombosis and haemostasis; ECAT), Dorothy Adcock-Funk, Elizabeth Plumhoff, and Elizabeth Van Cott (North American Specialized Coagulation Laboratory Association; NASCOLA), George A. Fritsma (Fritsmafactor.com), Kjell Grankvist, Zeliha Gunnur Dikmen, and Mads Nybo.

\section{References}

1 Lippi G, Cervellin G, Franchini M, Favaloro EJ. Biochemical markers for the diagnosis of venous thromboembolism: the past, present and future. J Thromb Thrombolysis 2010;30(4):459-471

2 Bates SM. D-dimer assays in diagnosis and management of thrombotic and bleeding disorders. Semin Thromb Hemost 2012;38(7): 673-682

3 Lippi G, Franchini M, Targher G, Favaloro EJ. Help me, Doctor! My D-dimer is raised. Ann Med 2008;40(8):594-605

4 Lippi G, Favaloro EJ. D-dimer measurement and laboratory feedback. J Emerg Med 2009;37(1):82-83, author reply 83

5 Favaloro EJ, Franchini M, Lippi G. Aging hemostasis: changes to laboratory markers of hemostasis as we age - a narrative review. Semin Thromb Hemost 2014;40(6):621-633

6 Lippi G, Favaloro EJ, Cervellin G. A review of the value of D-dimer testing for prediction of recurrent venous thromboembolism with increasing age. Semin Thromb Hemost 2014;40(6):634-639

7 Lippi G, Montagnana M. D-dimer testing in pregnancy: clinically useful, but at what cost? Ann Intern Med 2008;148(6):484, author reply 484-485

8 Bates SM, Jaeschke R, Stevens SM, et al; American College of Chest Physicians. Diagnosis of DVT: Antithrombotic therapy and prevention of thrombosis, 9th ed: American College of Chest Physicians evidence-based clinical practice guidelines. Chest 2012; 141(2 Suppl):e351S-418S

9 Bogavac-Stanojević N, Dopsaj V, Jelić-Ivanović Z, Lakić D, Vasić D, Petrova G. Economic evaluation of different screening alternatives for patients with clinically suspected acute deep vein thrombosis. Biochem Med (Zagreb) 2013;23(1):96-106

10 Lippi G, Cervellin G, Casagranda I, Morelli B, Testa S, Tripodi A. D-dimer testing for suspected venous thromboembolism in the emergency department. Consensus document of AcEMC, CISMEL, SIBioC, and SIMeL. Clin Chem Lab Med 2014;52(5):621-628

11 Lippi G, Plebani M. False myths and legends in laboratory diagnostics. Clin Chem Lab Med 2013;51(11):2087-2097

12 Hogg K, Wells PS, Gandara E. The diagnosis of venous thromboembolism. Semin Thromb Hemost 2012;38(7):691-701

13 Levi M, van der Poll T. A short contemporary history of disseminated intravascular coagulation. Semin Thromb Hemost 2014; 40(8):874-880

14 Dentali F, Squizzato A, Marchesi C, Bonzini M, Ferro JM, Ageno W. D-dimer testing in the diagnosis of cerebral vein thrombosis: a systematic review and a meta-analysis of the literature. J Thromb Haemost 2012;10(4):582-589

15 Karska-Basta I, Kubicka-Trzaska A, Pogrzebielski A, RomanowskaDixon B. A new insight into retinal vein occlusion pathogenesis. Klin Oczna 2013;115(4):269-274

16 Cervellin G, Lippi G. Of MIs and men-a historical perspective on the diagnostics of acute myocardial infarction. Semin Thromb Hemost 2014;40(5):535-543

17 Wiseman S, Marlborough F, Doubal F, Webb DJ, Wardlaw J. Blood markers of coagulation, fibrinolysis, endothelial dysfunction and inflammation in lacunar stroke versus non-lacunar stroke and non-stroke: systematic review and meta-analysis. Cerebrovasc Dis 2014;37(1):64-75

18 McDermott MM, Liu K, Ferrucci L, et al. Circulating blood markers and functional impairment in peripheral arterial disease. J Am Geriatr Soc 2008;56(8):1504-1510

19 Salvagno GL, Targher G, Franchini M, Lippi G. Plasma D-dimer in the diagnosis of acute aortic dissection. Eur Heart J 2008;29(9): 1207, author reply 1207-1208

20 Oshiro A, Yanagida Y, Gando S, Henzan N, Takahashi I, Makise H. Hemostasis during the early stages of trauma: comparison with disseminated intravascular coagulation. Crit Care 2014;18(2):R61

21 Lippi G, Veraldi GF, Fraccaroli M, Manzato F, Cordiano C, Guidi G. Variation of plasma D-dimer following surgery: implications for prediction of postoperative venous thromboembolism. Clin Exp Med 2001;1(3):161-164

22 Rodelo JR, De la Rosa G, Valencia ML, et al. D-dimer is a significant prognostic factor in patients with suspected infection and sepsis. Am J Emerg Med 2012;30(9):1991-1999

23 Gomes M, Khorana AA. Risk assessment for thrombosis in cancer. Semin Thromb Hemost 2014;40(3):319-324

24 Danese E, Montagnana M, Cervellin G, Lippi G. Hypercoagulability, D-dimer and atrial fibrillation: an overview of biological and clinical evidence. Ann Med 2014;46(6):364-371

25 Dempfle CE. D-dimer: standardization versus harmonization. Thromb Haemost 2006;95(3):399-400

26 Madoiwa S, Kitajima I, Ohmori T, Sakata Y, Mimuro J. Distinct reactivity of the commercially available monoclonal antibodies of D-dimer and plasma FDP testing to the molecular variants of fibrin degradation products. Thromb Res 2013;132(4):457-464

27 Crowther MA, Bates SM, Keeney M, Raby A, Flynn G. Humanderived D-dimer for external quality assessment: results of four surveys in Ontario. Am J Clin Pathol 2008;130(5):805-810

28 Olson JD, Cunningham MT, Higgins RA, Eby CS, Brandt JT. D-dimer: simple test, tough problems. Arch Pathol Lab Med 2013;137(8): 1030-1038

29 Plebani M, Favaloro EJ, Lippi G. Patient safety and quality in laboratory and hemostasis testing: a renewed loop? Semin Thromb Hemost 2012;38(6):553-558

30 Favaloro EJ, Lippi G. Laboratory reporting of hemostasis assays: the final post-analytical opportunity to reduce errors of clinical diagnosis in hemostasis? Clin Chem Lab Med 2010;48(3): 309-321

31 Raskob GE, Angchaisuksiri P, Blanco AN, et al; ISTH Steering Committee for World Thrombosis Day. Thrombosis: a major contributor to global disease burden. Semin Thromb Hemost 2014;40(7):724-735

32 Schouten HJ, Geersing GJ, Koek HL, et al. Diagnostic accuracy of conventional or age adjusted D-dimer cut-off values in older patients with suspected venous thromboembolism: systematic review and meta-analysis. BMJ 2013;346:f2492

33 Bonar R, Favaloro EJ, Adcock DM. Quality in coagulation and haemostasis testing. Biochem Med 2010;20(2):184-199

34 Reber G, de Moerloose P. Standardization of D-dimer Testing. In: Quality in Laboratory Hemostasis and Thrombosis, 2nd ed. Kitchen S, Olson JD, Preston FE, eds. Oxford, United Kingdm: John Wiley \& Sons; 2013

35 Medved L, Weisel JW; Fibrinogen and Factor XIII Subcommittee of Scientific Standardization Committee of International Society on Thrombosis and Haemostasis. Recommendations for nomenclature on fibrinogen and fibrin. J Thromb Haemost 2009;7(2): 355-359

36 Favaloro EJ, Plebani M, Lippi G. Regulation in hemostasis and thrombosis: part I-in vitro diagnostics. Semin Thromb Hemost 2013;39(3):235-249 